\title{
Prevalence of Risk Factors of Thromboembolic Complications in Women after Major Joint Arthroplasty in the Republic of Sakha (Yakutia)
}

\author{
Gennady A. Palshin, $\mathrm{PhD}, \mathrm{ScD}^{1^{*}}$; Stepan S. Pavlov${ }^{1}$; Mikhail M. Vinokurov, PhD, ScD ${ }^{1}$; \\ Natalia I. Douglas, $\mathrm{PhD}, \mathrm{ScD}^{1}$; Rosa D. Philippova, $\mathrm{PhD}, \mathrm{ScD}^{1}$; Valery E. Volovik, $\mathrm{PhD}, \mathrm{ScD}^{2}$; \\ Anton A. Yakovlev, $\mathrm{PhD}^{3}$; Anatoly N. Komissarov, $\mathrm{PhD}^{3}$; Maria Yu. Markovchina, $\mathrm{PhD}^{1}$ \\ ${ }^{\prime}$ M. K. Ammosov North-Eastern Federal University, Yakutsk, Russia \\ ${ }^{2}$ Republican Hospital No.2 - Center for Emergency Medical Care, Yakutsk, Russia \\ ${ }^{3}$ Institute for Advanced Studies of Healthcare Specialists, Khabarovsk, Russia
}

\begin{abstract}
The aim of this study was to assess the risk factors for thromboembolic complications after total arthroplasty of large joints in women in Yakutia conditions to optimize the management tactics of this category of patients. The average age of women was $59.98 \pm 11.56$ years in the age range from 50 to 70 years. In order to validate the study, women were divided into 2 groups. The main group consisted of 284 women undergoing total knee arthroplasty (Group 1). The comparison group included 147 women undergoing total hip arthoplasty (Group 2). The study demonstrated that hypertension was more common in patients of Group 1 than in patients of Group 2. However, the incidence of coronary heart disease and heart rhythm disorder was detected most frequently in patients with total hip arthroplasty. Obesity, thrombosis of the veins of the lower extremities, and liver disease were detected with almost the same frequency in women with total knee arthroplasty and those with total hip arthroplasty. The frequency of occurrence of complications depending on the risk factors for thromboembolic complications and the type of surgical treatment of the joint was equal in the two groups of studied patients. (International Journal of Biomedicine. 2018;8(4):333-336.)
\end{abstract}

Key Words: thromboembolic complications $\bullet$ women $\bullet$ total arthroplasty $\bullet$ large joints

\section{Introduction}

A significant prevalence of degenerative-dystrophic diseases of the joints of the lower extremities leads to a further search for effective methods of treatment. ${ }^{(1-3)}$ Among the latter, arthroplasty of the joints occupies a rather significant place, which allows eliminating pain syndrome and restoring range of motion and supporting ability of the lower limb. ${ }^{(4,5)}$ The risk of venous thromboembolic complications is maximal precisely in orthopedic practice, especially in endoprosthetic replacement of large joints. According to the summary statistics by W. Geertsetal (2004), after endoprosthetics of large joints in the absence of thromboembolic complications prevention, the incidence of deep vein thrombosis in the lower extremities

*Corresponding author: Prof. Gennady A. Palshin, PhD, ScD. M. K. Ammosov North-Eastern Federal University. Yakutsk, the Sakha Republic, Russia.E-mail: palgasv@mail.ru reaches $40 \%$ to $80 \%$ and pulmonary embolism, $4 \%$ to $10 \%$. The frequency of symptomatic thromboembolic complications in hip joint arthroplasty on the background of thromboprophylaxis is, according to various sources, from $1.3 \%$ to $3.4 \%$, and in case of knee arthroplasty, from $1.7 \%$ to $2.8 \%$. $^{(6)}$ Interestingly, fatal pulmonary embolism has remained consistent in primary total hip arthroplasty and total knee arthroplasty, between 0.1 and $2 \%$, no matter which agents are used. ${ }^{(7,8)}$ According to Pedersen et al. ${ }^{(9)}$, a high level of comorbidity and general anaesthesia were strong risk factors for both venous thromboembolism and bleeding, with no difference between patients undergoing total hip and knee replacement. The assessment of the level of influence of various risk factors on the development of venous thromboembolic complications for many decades has been the subject of discussion in the medical literature, since an adequate prevention of venous thromboembolic complications is interconnected with the assessment of risk factors. ${ }^{(4,6,10)}$ Considering the above-mentioned, the goal of our study was to 
assess the risk factors for thromboembolic complications after total arthroplasty of large joints in women in Yakutia conditions to optimize the management tactics of this category of patients.

\section{Materials and Methods}

This work is based on the results of a prospective clinical study of female patients who underwent knee and hip joint arthroplasty between 01.01.2012 and 12.31.2014. The average age of women treated in the trauma and orthopedic department was $59.98 \pm 11.56$ years in the age range from 50 to 70 years. Large joint arthroplasty was performed in 592 female patients (Fig.1)

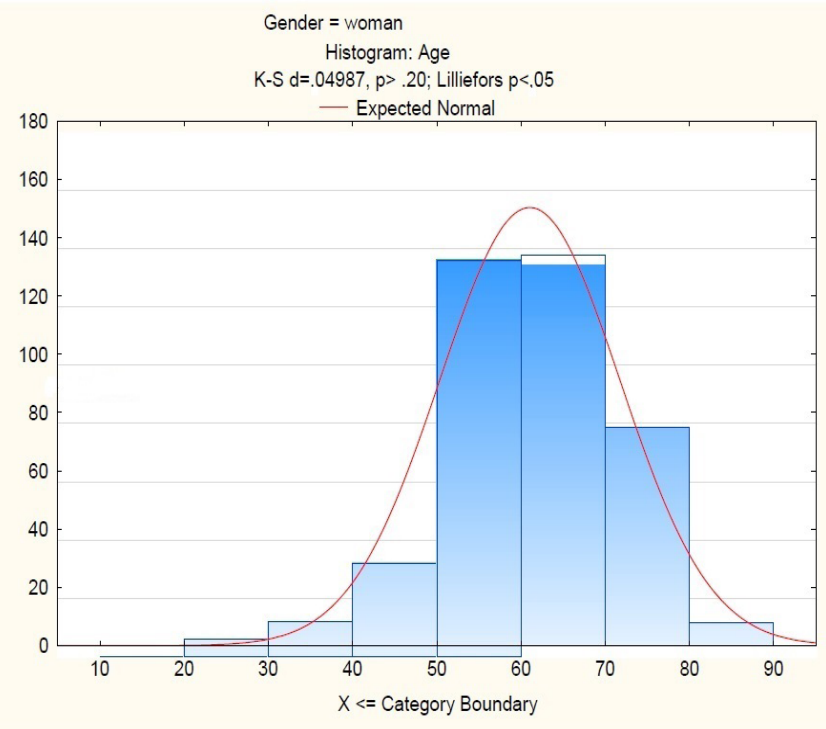

Fig.1. The incidence of large joint arthroplasty depending on age

Inclusion criteria: surgical treatment (total arthroplasty of the knee and hip joints) of degenerative-dystrophic diseases of the joint, false joint of the femur neck, systemic diseases, endoprosthesis instability, and written informed consent.

Exclusion criteria: lack of capacity to give informed consent; patient refusal.

The study was approved by the local Ethics Committee of M. K. Ammosov North-Eastern Federal University.

Patients eligible for all criteria included 431 people. In order to validate the study, women were divided into 2 groups. The main group consisted of 284 women undergoing total knee arthroplasty (Group 1). The comparison group included 147 women undergoing total hip arthoplasty (Group 2).

After the onset of hemostasis, all patients were prescribed prophylactic doses of anticoagulants in accordance with the clinical guidelines for the prevention of thromboembolic complications of the national standard of the Russian Federation. At discharge from the hospital, all patients were given recommendations for further prevention of thromboembolic complications; the goals of these drugs and possible complications were re-explained. It is also recommended to control the indicator of international normalised ratio to patients who took an indirect anticoagulant. Evaluation of the effectiveness of prophylactic treatment regimens for thromboembolic complications was carried out at the end of the course of prophylaxis and 12 months after surgical treatment.

Statistical analysis was performed using statistical software package SPSS version 19.0 (SPSS Inc, Chicago, IL). The normality of distribution of continuous variables was tested by one-sample Kolmogorov-Smirnov test. Quantitative parameters were presented as Median (Me) and 25th and 75th percentiles as Inter Quartile Range (IQR). Mann-Whitney U test was used to compare means of 2 groups of variables not normally distributed. The frequencies of categorical variables were compared using Pearson $\chi^{2}$ or Fisher's exact test, when appropriate. A value of $P<0.05$ was considered significant.

\section{Results and Discussion}

Many studies in the literature describe a number of risk factors that act as factors for the development of venous thromboembolic complications. These include coronary heart disease, arterial hypertension, chronic circulatory failure, varicose veins of the lower extremities, obesity, and a history of thrombosis. ${ }^{(11-22)}$ In systematic review performed by Zhang et al. ${ }^{(23)}$, older age, female gender, higher body mass index and bilateral surgery were found to be venous thromboembolism risk factors for both total hip arthroplasty and total knee arthroplasty. Considering the above-mentioned, we carried out an analysis of these concomitant diseases in order to determine their significant effect on venous thromboembolic complications in the studied patients.

Analysis of the clinical characteristics revealed that in all patients the most frequently associated diseases were obesity, arterial hypertension, and coronary heart disease (Table 1).

Table 1.

The frequency of concomitant diseases, depending on the type of joint replacement

\begin{tabular}{|l|c|c|c|}
\hline Concomitant pathology & $\begin{array}{c}\text { Group 1 } \\
(\mathrm{n}=284)\end{array}$ & $\begin{array}{c}\text { Group 2 } \\
(\mathrm{n}=147)\end{array}$ & $\mathrm{P}_{1-2}$ \\
\hline Obesity & $110(38.7 \%)$ & $68(46.2 \%)$ & 0.132 \\
\hline $\begin{array}{l}\text { Varicose veins of the } \\
\text { lower extremities }\end{array}$ & $79(27.8 \%)$ & $39(26.5 \%)$ & 0.776 \\
\hline Hypertension & $194(68.3 \%)$ & $82(55.8 \%)$ & 0.010 \\
\hline $\begin{array}{l}\text { Coronary heart disease } \\
75(26.4 \%)\end{array}$ & $55(37.4 \%)$ & 0.018 \\
\hline $\begin{array}{l}\text { Thrombosis of the veins } \\
\text { of the lower extremities in } \\
\text { history }\end{array}$ & $2(0.7 \%)$ & $4(2.7 \%)$ & 0.090 \\
\hline Heart rhythm disorder & $1(0.35 \%)$ & $8(5.4 \%)$ & 0.000 \\
\hline Hepatitis C. liver failure & $7(2.46 \%)$ & $4(2.7 \%)$ & 0.872 \\
\hline
\end{tabular}


Hypertension was more common among women in Group 1 $(68.3 \%)$ than among those in Group 2 (55.8\%). However, the incidence of coronary heart disease and heart rhythm disorder was detected most frequently in Group 2. Thrombosis of the veins of the lower extremities and liver disease were detected with almost the same frequency in women with knee prosthesis and those with hip prosthesis.

As can be seen from Table 2, the frequency of occurrence of complications depending on the risk factors for venous thromboembolic complications and the type of surgical treatment of the joint was equal in the two groups of studied patients.

Table. 2.

The frequency of complications depending on risk factors for thromboembolic complications and the type of joint replacement

\begin{tabular}{|l|c|c|c|c|}
\hline \multirow{2}{*}{\multicolumn{1}{|c|}{ Risk Factor }} & \multicolumn{2}{|c|}{$\begin{array}{c}\text { Complication* } \\
(\mathrm{n}=14)\end{array}$} & \multicolumn{2}{c|}{$\begin{array}{c}\text { No complication } \\
(\mathrm{n}=417)\end{array}$} \\
\cline { 2 - 5 } & Group 1 & Group 2 & Group 1 & Group 2 \\
\hline Obesity & 3 & - & 107 & 68 \\
\hline Varicose veins & 3 & 2 & 76 & 37 \\
\hline Hypertension & 3 & 2 & 147 & 80 \\
\hline Coronary heart disease & 1 & 1 & 74 & 54 \\
\hline $\begin{array}{l}\text { Thrombosis of the veins } \\
\text { of the lower extremities } \\
\text { in history }\end{array}$ & - & 1 & 2 & 3 \\
\hline Heart rhythm disorder & 1 & - & 6 & 8 \\
\hline
\end{tabular}

*- no statistically significant differences between Group 1 and Group 2

\section{In conclusion:}

The study demonstrated that hypertension was more common in patients with total knee arthroplasty than in patients with total hip arthroplasty. However, the incidence of coronary heart disease and heart rhythm disorder was detected most frequently in patients with total hip arthroplasty. Obesity, thrombosis of the veins of the lower extremities, and liver disease were detected with almost the same frequency in women with knee prosthesis and those with hip prosthesis. The frequency of occurrence of complications depending on the risk factors for venous thromboembolic complications and the type of surgical treatment of the joint was equal in the two groups of studied patients.

\section{Conflict of interest}

The authors declare that they have no competing interests.

\section{References}

1. Abeltsev V. P. Endoprosthetics of the hip joint at dysplastic coxatrosis (optimal treatment methods). Abstract of $\mathrm{ScD}$ Thesis. Moscow; 2004. [In Russian].
2. Shapovalov VM, Tikhilov PM. Total hip arthroplasty. In: The state and prospects of development of military traumatology and orthopedics: SPb., 1999;248:549-557. [In Russian].

3. Torchia ME, Klassen RA, Bianco AJ. Total hip arthroplasty with cement in patients less than twenty years old. Long-term results. J Bone Joint Surg Am. 1996;78(7):995-1003.

4. Tikhilov PM, Shapovalov VM. Guide to hip arthroplasty. SPb.: RNIITO n.a. RR Vreden; 2008. [In Russian].

5. Keggi KJ, Huo MH, Zatorski LE. Anterior approach to total hip replacement: surgical technique and clinical results of our first one thousand cases using non-cemented prostheses. Yale J Biol Med. 1993;66(3):243-56.

6. Kopenkin SS. [Prevention of venous thromboembolic complications in orthopedic surgery: new opportunities]. N.N. Priorov Journal of Traumatology and Orthopedics; 2010;(1):35-39. [Article in Russian].

7. Sheth NP, Lieberman JR, Della Valle CJ. DVT prophylaxis in total joint reconstruction.Orthop Clin North Am. 2010;41(2):273-80. doi: 10.1016/j.ocl.2010.02.001.

8. Lieberman JR, Hsu WK. Prevention of venous thromboembolic disease after total hip and knee arthroplasty. J Bone Joint Surg Am. 2005;87(9):2097-112.

9. Pedersen AB, Mehnert F, Sorensen HT, Emmeluth C, Overgaard S, Johnsen SP. The risk of venous thromboembolism, myocardial infarction, stroke, major bleeding and death in patients undergoing total hip and knee replacement: a 15-year retrospective cohort study of routine clinical practice. Bone Joint J. 2014;96-B(4):479-85. doi: 10.1302/0301-620X.96B4.33209.

10. Nikolenko VK, Buryachenko BP, Maksimov BI. [Features of modern surgical treatment of bilateral coxarthrosis]. N.N. Priorov Journal of Traumatology and Orthopedics; 2006;(4):34-41. [Article in Russian].

11. Won MH, Lee GW, Lee TJ, Moon KH. Prevalence and risk factors of thromboembolism after joint arthroplasty without chemical thromboprophylaxis in an Asian population. J Arthroplasty. 2011;26(7):1106-11 doi: 10.1016/j. arth.2010.11.005.

12. Zhang ZH, Shen B, Yang J, Zhou ZK, Kang PD, Pei FX. Risk factors for venous thromboembolism of total hip arthroplasty and total knee arthroplasty: a systematic review of evidences in ten years. BMC Musculoskelet Disord. 2015;16:24. doi: 10.1186/s12891-015-0470-0.

13. Sweetland S, Green J, Liu B, Berrington de González A, Canonico M, Reeves G, Beral V; Million Women Study collaborators. Duration and magnitude of the postoperative risk of venous thromboembolism in middle aged women: prospective cohort study. BMJ. 2009;339:b4583. doi: 10.1136/bmj.b4583.

14. Feng B, Lin J, Jin J, Qian WW, Wang W, Weng XS. Thirtyday Postoperative Complications following Primary Total Knee Arthroplasty: A Retrospective Study of Incidence and Risk Factors at a Single Center in China. Chin Med J (Engl). 2017;130(21):2551-2556. doi: 10.4103/0366-6999.213071.

15. Plante S, Belzile EL, Fréchette D, Lefebvre J1. Analysis of contributing factors influencing thromboembolic events after total knee arthroplasty. Can J Surg. 2017;60(1):30-36.

16. Singh JA, Jensen MR, Harmsen WS, Gabriel SE, Lewallen DG. Cardiac and thromboembolic complications and mortality in patients undergoing total hip and total knee arthroplasty. Ann Rheum Dis. 2011;70(12):2082-8. doi: 10.1136/ard.2010.148726. 17. Memtsoudis SG, Ma Y, González Della Valle A, Mazumdar M, Gaber-Baylis LK, MacKenzie CR, Sculco TP. Perioperative outcomes after unilateral and bilateral total 
knee arthroplasty. Anesthesiology. 2009;111(6):1206-16. doi: 10.1097/ALN.0b013e3181bfab7d.

18. Memtsoudis SG, Della Valle AG, Besculides MC, Esposito M, Koulouvaris P, Salvati EA. Risk factors for perioperative mortality after lower extremity arthroplasty: a populationbased study of 6,901,324 patient discharges. J Arthroplasty. 2010;25(1):19-26. doi: 10.1016/j.arth.2008.11.010.

19. Machlus KR, Aleman MM, Wolberg AS. Update on venous thromboembolism: risk factors, mechanisms, and treatments. Arterioscler Thromb Vasc Biol. 2011;31(3):476-8. doi: 10.1161/ATVBAHA.111.223008.

20. Pedersen AB, Sorensen HT, Mehnert F, Overgaard S, Johnsen SP. Risk factors for venous thromboembolism in patients undergoing total hip replacement and receiving routine thromboprophylaxis. J Bone Joint Surg Am.
2010;92(12):2156-64. doi: 10.2106/JBJS.I.00882. 21. Singh JA, Jensen MR, Harmsen WS, Gabriel SE, Lewallen DG. Cardiac and thromboembolic complications and mortality in patients undergoing total hip and total knee arthroplasty. Ann Rheum Dis. 2011;70(12):2082-8. doi: 10.1136/ard.2010.148726.

22. Dua A, Neiva S, Sutherland A. Does previous varicose vein surgery alter deep vein thrombosis risk after lower limb arthroplasty? Orthop Surg. 2012;4(4):222-6. doi: 10.1111/ os. 12003 .

23. Zhang ZH, Shen B, Yang J, Zhou ZK, Kang PD, Pei FX. Risk factors for venous thromboembolism of total hip arthroplasty and total knee arthroplasty: a systematic review of evidences in ten years. BMC Musculoskelet Disord. 2015;16:24. doi: 10.1186/s12891-015-0470-0. 